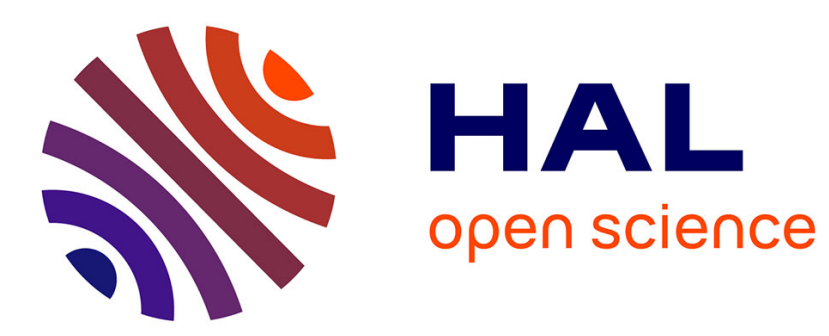

\title{
How significant is yardstick competition among governments? Three reasons to dig deeper \\ Pierre Salmon
}

\section{To cite this version:}

Pierre Salmon. How significant is yardstick competition among governments? Three reasons to dig deeper. 2013. hal-00830872

\section{HAL Id: hal-00830872 \\ https://hal.science/hal-00830872}

Preprint submitted on 5 Jun 2013

HAL is a multi-disciplinary open access archive for the deposit and dissemination of scientific research documents, whether they are published or not. The documents may come from teaching and research institutions in France or abroad, or from public or private research centers.
L'archive ouverte pluridisciplinaire HAL, est destinée au dépôt et à la diffusion de documents scientifiques de niveau recherche, publiés ou non, émanant des établissements d'enseignement et de recherche français ou étrangers, des laboratoires publics ou privés. 
This version: 12 April 2013

\title{
How significant is yardstick competition among governments? Three reasons to dig deeper
}

\author{
by \\ Pierre Salmon \\ Laboratoire d'Economie et de Gestion \\ Université de Bourgogne and CNRS, Dijon, France \\ pierre.salmon@u-bourgogne.fr
}

\begin{abstract}
The significance of yardstick competition among governments is now confirmed with regard to fiscal variables. This is an important result but the significance of the mechanism must also be sought in a context broader than that of fiscal federalism and without limitation to relations and processes fully observable. Three points are made. Even in the case of governments trying to mimic each other over a single variable, additional variables are involved in an important way. Yardstick competition can be latent without being ineffective. Its major effect, then, is to set bounds to the choices that office-holders could think of making. Finally, the mechanism is a hidden albeit essential component of the political and economic system, which would look quite different if voters could not make comparisons across jurisdictions and there were thus no yardstick competition, even of the latent variety.
\end{abstract}




\section{Introduction}

Yardstick competition among governments occurs when, to remain in office, incumbents attempt to make the government they lead as well placed as possible in the cross-jurisdiction comparisons that are, or could be, made by their 'own' voters. Its relevance stems from voters being in a situation of information asymmetry vis-à-vis incumbents. Ordinary voters cannot directly observe the cost of the services governments provide or whether decisions made are the best ones given the circumstances. Yardstick competition cannot eliminate information asymmetry but it may mitigate its consequences.

The mechanism was presented informally in Salmon (1987). Following Besley and Case (1995), it became an object of theoretical elaboration and empirical investigation mainly in the domain of fiscal federalism. The empirical studies (largely based on spatial econometrics) are particularly innovative and impressive. Thanks to them it is now well confirmed empirically that yardstick competition among local or regional governments can have a significant influence on their fiscal decisions (taxation and expenditures) and/or on the way these decisions affect the electoral prospects and popularity of incumbents. For a mechanism to be significant in that sense is important if it is to be more than potentially interesting (Bordignon et al. 2003, p. 215). If such significance had not been established, yardstick competition would not have attracted the attention of a relatively sizeable number of researchers.

Yet, I will try to show that the significance of yardstick competition among governments is both broader and more profound than that investigated empirically so far. One obvious reason for it to be broader, directly related to the limits of the domain of fiscal federalism, is that variables other than fiscal ones can also be objects of yardstick competition -- laws and regulations of various types, for example, or macroeconomic variables such as economic growth, inflation and unemployment. Another obvious reason for a broader significance, also related to its fiscal federalism habitat, is that yardstick competition need not only take place among local and regional governments within a country but may also take place at the international level among central governments.

Why also 'deeper'? Again, the nature of the fiscal federalism domain explains in part why the empirical research involving yardstick competition has managed to remain 
close to the observational level. Two patterns are followed in the empirical studies involving yardstick competition - both present in Besley and Case (1995) but only one of the two in other studies. ${ }^{1}$ In the first, the presence of yardstick competition is detected if the popularity or electoral score of incumbents is affected not only by fiscal decisions made in their 'own' jurisdictions but also by the decisions made in neighbouring ones. That mechanism corresponds to what has been called 'yardstick voting' (or 'comparative voting') rather than directly to yardstick competition, but there is a presumption that yardstick voting will induce incumbents to engage in yardstick competition proper. The work to be done to confirm the relevance of yardstick voting in given settings and data sets is mainly statistical (see Besley and Case 1995, Revelli 2002, Vermeir and Heyndels 2006, Bosch and Solé-Ollé 2007).

In the second pattern, the starting point is a purely empirical regularity: fiscal interaction among neighbouring jurisdictions. Fiscal choices in one jurisdiction are related to fiscal choices in others. How is the interdependence to be explained? It may be due to a common shock or trend, to expenditure spillovers, to mobility-based (e.g. $\operatorname{tax}$ ) competition or to yardstick competition, to mention the four main causes discussed in the literature. ${ }^{2}$ One way to single out yardstick competition is to test whether some purely political characteristics of the decision context have an effect on the interaction. Variables used for that purpose include the strength of the majority enjoyed by the incumbent, whether the incumbent can be a candidate again or faces a term limit, and the proximity of the next election. Contrary to yardstick competition, the other mechanisms which can cause the observed interaction have no relation with these variables. Thus if any one of the latter is found to have an effect on the existence or strength of the interaction, this is interpreted as supporting the hypothesis that yardstick competition plays a role in it. Studies based on that research strategy include Besley and Case (1995), Bordignon et al. (2003), Solé-Ollé (2003), Allers and Elhorst (2005), Elhorst and Fréret (2009), Bartolini and Santolini (2012). ${ }^{3}$

\footnotetext{
1 Asking directly to decision-makers what causes their decisions is unusual in economics. The nonetheless seminal article of Ashworth and Heyndels (1997) is an exception.

${ }_{2}$ Another possible source is inter-communication among office-holders belonging to the same political party (Santolini 2009, see also Wrede 2001).

3 To disentangle tax competition and yardstick competition, one argument used in particular by Feld et al. (2003) is that the former induces a diminution of taxation, whereas the latter is compatible with or induces an increase. But see also Fiva and Rattso (2009).
} 
Again, although increasingly subtle and sophisticated (Revelli 2012), the work involved is mainly econometric. Reaction coefficients, concerning values of a single fiscal variable across jurisdictions, are estimated. But they are estimated from the relatively small variations that can normally be observed. It is not really known how the estimated reaction coefficients would fare under much larger variations within the jurisdictions. In other words, we are not exactly on the surface but only at a small distance below. Even remaining within the domain of fiscal federalism, there might be a case for exploring effects at a deeper level. But the case is more compelling when the scope of yardstick competition is extended to non-fiscal variables and interactions between central governments at the international level.

The two patterns just discussed do not offer the same possibilities. The second proved essential to put yardstick competition on the map, so to say, but the first -yardstick voting presumed to induce yardstick competition -- seems more able to serve as a starting point for new reflections. It is more versatile or open, with a capacity to enter as an element in different types of reasoning or studies. Let me note a few possibilities. The pattern allows that voters' comparisons, electoral effects of these comparisons, and politicians' response to these effects are sequences that can be investigated or discussed separately. This is an inducement to consider the dynamics and shape of the overall process. The pattern also allows non-coincidence between the variables concerned by voter comparisons and the variables involved in incumbents' response to these comparisons. That feature is more particularly valuable when the first set includes variables like economic growth or the performance of students rather than the rate of some tax or the level of some expenditure. Finally, the pattern makes possible that comparisons are anticipated, taken care of, consequently unobserved, and none the less remaining essential. That possibility allows forays into a reality that lies beyond the observable or even the actual.

Inspired by a methodological perspective close to "scientific realism" (incidentally, quite central in traditional economics), ${ }^{4}$ the following sections explore

\footnotetext{
${ }^{4}$ Going beyond the observable or even the actual has been recommended by many well-known philosophers of science - for instance, Roy Bhaskar (1975), Nancy Cartwright (1983), Ronald Giere (1985), Karl Popper (1963) and Wesley Salmon (1984). Their quite different views about the relationship between reality and observation are part of or close to "scientific realism". Observable or even actual regularities are not the only material of reality and should not constitute the only object of scientific
} 
layers of reality increasingly distant from pure observation (not to speak of measurement). In Section 2, I use the flexibility inherent in the first pattern to review more attentively than is done usually the variables that may be directly or indirectly affected by yardstick competition. A major distinction, which has not much sense in the case of fiscal variables but a lot in other settings, is between variables that are mainly policy outcomes and variables that are mainly policy instruments. Section 3 is about what I call 'bounds-setting' or 'latent' yardstick competition. The anticipation of yardstick voting induces office-holders to set bounds to the decisions they might make. The main determinants of these bounds are discussed with the help of a heuristic model, presented in geometrical terms. Another heuristic model, reflecting counterfactual reasoning, is at the centre of Section 4, whose purpose is to show that yardstick competition has a major, even if hidden, influence on policy-making and systemic arrangements. Section 5 is a conclusion.

Four caveats must be formulated at this stage. First, I refer to voters mainly for convenience. Voting is only one form of support to rulers. That makes yardstick competition relevant in (almost) all kinds of real-world political regimes, including those in which elections do not count. Second, yardstick competition is horizontal when the jurisdictions compared are at the same level of the governmental system and vertical when they are located at different levels. In this paper, I consider only the horizontal case -- for vertical competition, or for a framework which allows comparisons of all governments whatever their location, see Breton (1996, 2006). Third, I also abstain from discussing what might be called 'top-down horizontal yardstick competition' -that is, horizontal intergovernmental comparisons made not from below by voters but from above by a government or an authority higher up in the system (Maskin et al. 2000). ${ }^{5}$ Finally I do not discuss (except tangentially in Section 4) the possibility of yardstick competition having perverse effects, as demonstrated in particular by Besley and Smart (2007). In fact, it is enough to look at the financial markets to be aware that

investigation. With important differences among these philosophers, items such as capacities, propensities, causal processes, hidden mechanisms, possibilities and impossibilities may be considered parts of reality and references to them legitimate ingredients of scientific knowledge.

5 I neglect also horizontal yardstick competition generated by local officials using cross-jurisdiction comparisons to assess the performance of their subordinated administrations (Revelli and Tovmo 2007). 
high-powered incentives may be harmful. And there are other ways than through incentives for yardstick competition to be possibly or sometimes harmful.

\section{Variables concerned by yardstick competition}

Assume a variable $\mathrm{X}$ whose values (or changes therein) are compared across jurisdictions by voters. These comparisons may have an effect on the popularity and electoral prospect of incumbents in the different jurisdictions (yardstick voting). Incumbents respond to that possibility by trying to be well placed in voters' comparisons. This is usually interpreted as each incumbent trying to mimic the values taken by $\mathrm{X}$ in neighbouring jurisdictions. Although, I find that interpretation somewhat conservative (in particular, why not try to surpass the achievements of others?), I adopt it for convenience. The question in need of more attention is what the process of mimicking or trying to mimic consists of exactly. I discuss it in the setting of fiscal federalism first, in a broader context afterwards.

\subsection{Within the context of fiscal federalism}

In the case of variables like tax rates, the process is reduced to a single decision. Mimicking consists in setting or changing the tax rate concerned. The action, once decided, is generally assumed to be immediate and to encounter no obstacle. The same is true of most of the other fiscal variables discussed in the literature.

I note, however, three complications. First, there are indirect effects. They work notably through the budget constraint (Allers and Elhorst 2011). ${ }^{6}$ Changing the rate of some tax may entail changing the rate of some other tax or the level of some expenditure. Second, it may not be very rational on the part of voters to compare taxes independently of expenditures or vice versa. As acknowledged by several authors, voters are more likely to consider taxation for given expenditures or expenditures for given taxes. One way to take into account that complication is to assume that our variable $\mathrm{X}$ is synthetic and reflects somehow both policy output and taxation. In Breton (1996, 2006, see also Breton and Fraschini 2003), voters compare across jurisdictions the tightness of Wicksellian connections (that is, connections between output quantities 
and tax prices) and in Geys (2006) they compare efficiency rates (that is, to simplify, output over expenditure, or 'value for money'). But if $\mathrm{X}$ is a complex or multidimensional variable like those, mimicking may be undertaken in different ways. For instance, it may be achieved by varying the numerator, the denominator or both if $\mathrm{X}$ is a ratio, by varying any of the elements that $\mathrm{X}$ aggregates if it is a sum. Jurisdictions may make different choices in that regard. Several policy variables will thus be involved simultaneously (with the additional complication that some are adjustable immediately and others only over time). Third, if $\mathrm{X}$ is complex in the sense above, an empirical study might miss it and seek wrongly to detect effects of yardstick competition on some variable which is only an element of $\mathrm{X}$. This will normally cause the significance of the mechanism to be underestimated.

\subsection{Outside the context of fiscal federalism}

The complications just discussed seem small and manageable compared to those to be expected if yardstick competition is studied in a context other than fiscal federalism. Suppose for instance that our variable $\mathrm{X}$ is economic growth (or its outcome in terms of income levels). Comparisons made by voters may apply to X more or less as they apply to fiscal variables. But the nature of incumbents' response and, as a consequence, the responsibility that voters impute to incumbents are different. Reaching a higher level of economic growth, or containing a growing comparative gap in income per capita, cannot be decided and implemented in the same way as deciding and implementing a change in a tax rate. One difference is the time span necessary to 'mimic'. Increasing a growth rate so as to reduce significantly a difference in income will take years instead of minutes. But another difference is even more important for our purpose. If $\mathrm{X}$ is a growth rate or an income level, purporting to mimic the value of $\mathrm{X}$ involves necessarily and most conspicuously other variables than $\mathrm{X}$ itself.

Information asymmetry implies that voters cannot judge policy instruments otherwise than indirectly - that is, by assessing outcomes. But the distinction between policy instruments and policy outcomes does not make sense in the case of most fiscal variables. A tax is simultaneously a policy instrument and a policy outcome affecting

\footnotetext{
${ }^{6}$ Allers and Elhorst (2011) is about fiscal interaction, not yardstick competition. However, as they suggest, the extension of their analysis to the latter seems relatively straightforward.
} 
voters directly. Yardstick competition over growth rates is another matter. A rough distinction among the variables involved seems fruitful in that case. Growth rates may be considered policy outcomes and thus of some direct interest to voters. Subsidies to research, investments in infrastructures or the liberalization of external trade are instruments whose capacity to enhance growth may be assumed to be gauged by officeholders rather than by voters (this is a simplification of course). If we interpret the matter in that way, modes of interaction among governments such as diffusion of policy innovations, the following of best practice and 'laboratory federalism' should not be confused, as has been occasionally the case, with yardstick competition. Inasmuch as they are triggered (as instruments) by it, they may be considered to be its indirect effects in some sense. ${ }^{7}$

Indirect effects in another, more restricted, sense concern not instruments but outcomes, observable by voters, other than the outcome which is the object of yardstick competition (growth in the foregoing discussion). As in the setting of fiscal federalism, the interaction with the latter is typically a consequence of the budget constraint. For instance, via that constraint, yardstick competition over growth may affect outcomes of interest to voters in the domain of cultural or environmental policies.

To conclude that section, let me just note that, already in the setting of fiscal federalism but more importantly when the context is enlarged, more variables are involved by yardstick competition (over a single outcome, not to speak of yardstick competition taking place simultaneously over different outcomes) than is assumed in the empirical literature. This is by no means a criticism of that literature. The nature of the links between yardstick voting and many of the variables it affects makes them difficult to disentangle from other influences and precludes in general their quantitative analysis. The purpose of the foregoing discussion is thus mainly to suggest that even at the level of actual and often observable variables there are reasons to consider the significance of yardstick competition as generally underestimated.

\footnotetext{
${ }^{7}$ It must be stressed that yardstick competition over outcomes does not imply mimicking instruments. To mimic outcomes a government looking for appropriate instruments may seek inspiration in what is done elsewhere or it may follow its own way. This explains the large variety of legal arrangements and policies observed even among countries particularly likely to be objects of yardstick competition. See Salmon (2006) for the case of corporate governance.
} 


\section{Yardstick competition as a bounds-setting mechanism}

\subsection{Latent competition}

Yardstick competition, like competition in general, may be quite visible in the sense that efforts made by each participant to come ahead of others -- or not to fall behind -are observable. But often, yardstick competition, again like competition in general, is latent. All is quiet. Participants seem to care only about their own affairs, with no attention given to what the others are doing. In the absence of exogenous shocks, little of the mechanism uncovers itself as a subject of observation or empirical investigation. But competition is there nonetheless, limiting more or less severely the decisions that participants could make.

In the case of yardstick competition among governments, voters have the main role. But, in normal circumstances, voters have little incentive to look at the situation elsewhere, to make comparisons. Why would voters in jurisdiction $\mathrm{J}$ notice a one per cent increase in the property tax set in neighbouring jurisdictions? What is amazing is not that such an increase has little effect on their behaviour or on tax setting in J, but that it has an effect at all. But what would happen if the tax on neighbouring jurisdiction doubled or tripled? Or, rather, what would happen if the tax in other jurisdictions remained constant but the tax in $\mathrm{J}$ doubled or tripled? Would voters in $\mathrm{J}$ remain inattentive?

Thus, in the case of latent yardstick competition, the normal situation is that voters do not make comparisons. But the presumption that they would in case of larger cross-jurisdictions differences does have an impact on policy-making. In other words, in the case of latent yardstick competition, the main effect is to set bounds on policy choices. Let us concentrate on negative relative performance (hereafter referred to as a 'negative performance gap'). It may take the form of an increase in tax burden higher, a rate of growth lower, a rate of unemployment higher or a level of student achievements lower than elsewhere. In a given jurisdiction two variables will determine the degree to which incumbents feel constrained by the cross-jurisdiction comparisons in which voters could engage. One is the magnitude of the loss in popular or electoral support that a negative gap would generate. The second is the level of support loss that the incumbent would judge intolerable. The way these two variables interact so as to limit 
our incumbent's decisions may be analyzed with the help of the following model, exposed in a geometrical mode.

\section{2. $A$ model $^{8}$}

Assume only one policy outcome. With regard to that outcome, and by comparison with other jurisdictions, assume a possible negative performance gap measured objectively. Eventually, such a gap would cause discontent among voters and reduce support to the incumbent. For a given jurisdiction, the larger the gap, the larger the support loss that the incumbent may be expect. That relation is the sum of two relationships. The first, pertaining to information, concerns the way objective gaps translate into perceived gaps. The obstacles to widespread perception are considerable. There is no need to enter into details, however, to predict the average outcome: in a given jurisdiction, the larger the objective gap, the more it is perceived by voters and/or public opinion. The second relationship, more political (the first is also in part political but less so), relates to the effect of a perceived gap on political support to the incumbent. At an aggregate level, for a given jurisdiction, the larger the perceived gap, the larger the support loss.

In Figure 1, the two variables 'negative performance gap' and 'support loss' are measured along the horizontal and vertical axes respectively. For any jurisdiction, the aggregate relation between gap and support loss (itself the sum of two relations, as just noted) can be assumed to have an $S$-shape, as illustrated in Figure 1 by curves $\mathbf{V}$ and $\mathbf{W}$. In the case of $\mathbf{V}$, the two underlying mechanisms operate with maximum vigour. Some sectors of opinion would perceive the performance gap as soon as it appears and even a small perceived gap would entail some support loss. Then, one-unit increases in the gap would have an increasing effect on the amount of that loss (the curve becomes steeper). Other people, less perceptive, discover the gap when it is bigger, conversations and the media focus on it to an increasing degree, etc. When the loss generated by the gap is widespread, however, one-unit increases in that gap would have a decreasing effect on support loss. The reasons for this are that most people who could be informed about the existence of a gap have already been informed, that the discontent of informed people is already so high that the gap becoming even more serious does not decrease their

\footnotetext{
${ }^{8}$ The model is derived from one presented at a seminar at the University of Siena in 1993 and included in Salmon (1997).
} 
support very much, and that a fraction of the population remains more or less unconcerned by the gap whatever its level.

\section{[Figure 1 about here]}

Curve $\mathbf{W}$ corresponds to a situation or jurisdiction in which the mechanisms underlying the overall relation between gap and support loss are weaker. That difference may result from obstacles to assessing the relative performance of the jurisdiction, which may be special in one way or the other. It can also be the result of geographical, linguistic or other obstacles to cross-border information flows. It can arise from the population being relatively unwilling to engage in comparisons. These various factors can interact. Anyhow, at some level of the gap, the incumbent must expect that there will be some loss of support and that it will increase with the gap. Thus curve $\mathbf{W}$ has the same general shape as curve $\mathbf{V}$.

Let me now consider incumbent's response to support loss. It will be determined in part by the political and electoral set-up. A given level of support loss will not have the same effect under a system of majority rule allowing rapid alternation in office of competing political parties and in which, thus, office-holding is highly 'contestable', and under a system in which voters cannot but with great difficulty get rid of rulers whom they do not like. But another determinant is the specific objective situation of incumbents: whether or not they are initially supported by a large majority, how much time remains before the next election takes place, whether or not incumbents can be candidates again or face term limits. And there are more subjective determinants like the degree of utility given by incumbents to remaining in office, their degree of risk aversion, how they perceive the various costs involved in limiting the gap. The model is incomplete in particular inasmuch as it does not make explicit these determinants. Overall, however, we may assume that incumbents will set some bounds to the performance-induced support loss they are willing to tolerate

In Figure 1, we consider three values of these bounds. At point $\mathbf{T}_{\mathbf{S}}$, only a 'small' support loss seems tolerable to the incumbent, whereas points $\mathbf{T}_{\mathbf{L}}$ and $\mathbf{T}_{\mathbf{V L}}$ correspond to an incumbent accepting at the limit 'large' and 'very large' support losses. Thus, decision-making by an incumbent has two determinants, which can be called, for 
convenience, 'sensitivity to underperformance' and 'sensitivity to support loss'. Call $\mathbf{V}_{\mathbf{i}}$ the curves of which $\mathbf{V}$ and $\mathbf{W}$ are exemplars, and $\mathbf{T}_{\mathbf{j}}$ the horizontal lines of which the horizontal lines passing through $\mathbf{T}_{\mathbf{S}}, \mathbf{T}_{\mathbf{L}}$ and $\mathbf{T}_{\mathbf{V L}}$ are exemplars. An intersection point between a $\mathbf{V}_{\mathbf{i}}$ curve and a $\mathbf{T}_{\mathbf{j}}$ line reflects the maximum negative gap which the incumbent in a jurisdiction will self-impose as a constraint to its policy decisions.

Among the above determinants of incumbent's response to support loss, let us assume away incumbent's specific political situation and incumbent's subjective calculations. What remains is the contestability dimension of the institutional and in particular electoral set-up. That set-up concerns jurisdictions rather than incumbents. Thus, each jurisdiction can be represented by the intersection point of a $\mathbf{V}_{\mathbf{i}}$ curve (sensitivity to underperformance) and a $\mathbf{T}_{\mathbf{j}}$ horizontal line (sensitivity to support loss). Let us compare different cases. Point $\mathbf{A}$ reflects a situation in which office-holding is highly contestable and in which negative gaps cause a support loss rapidly. A small objective gap (a) would cause a support loss $\left(\mathbf{T}_{\mathbf{S}}\right)$, which, although also small, would seem intolerable to office-holders. Thus, in that jurisdiction policy-making is highly constrained by yardstick competition. At point $\mathbf{D}$, the two considerations converge toward the tolerance of a large negative gap (inferior only to d). Policy-making is much less constrained. In other words, important variations in performance may be observed. Points $\mathrm{B}$ and $\mathbf{C}$ reflect cases which are intermediate for different reasons. Lastly, if tolerance of support loss is $\mathbf{T}_{\mathbf{V L}}$ and the $\mathbf{V}_{\mathbf{i}}$ curve is $\mathbf{W}$-- becoming horizontal before reaching $\mathbf{T}_{\mathbf{V L}}$-- yardstick competition does not work at all whatever the level of the gap.

\subsection{Discussion}

We mentioned in Section 1 a number of studies confirming the presence of yardstick competition, but there are also some which do not. Negative results are reported by Foucault et al (2008), for instance. It must also be acknowledged that scepticism about the capacity of voters to make cross-jurisdiction comparisons is often expressed (see, for instance, Hindriks and Lockwood 2009). In fact, many obstacles to the working of the mechanism come to mind. In particular, its relevance in non-democratic settings may seem implausible. But the model above can accommodate all kinds of reservations or objections, all of them reflected in the shape of the $\mathbf{V}_{\mathbf{i}}$ curves and/or in the position of 
the $\mathbf{T}_{\mathbf{j}}$ lines. Figure 1 explains why the model is compatible with small gaps remaining unnoticed and large gaps remaining tolerated. The effect of obstacles is simply a greater tolerance of underperformance - that is, bounds on incumbent's choices that are less constraining.

In the foregoing discussion, these bounds were supposed to be self-imposed. This assumes that the incumbent, or the incumbent party, wants to remain in office. As stressed in the theoretical analyses of yardstick competition (e.g., Besley and Smart 2007), an incumbent may decide to give up re-election and shirk in the present as much as possible. Then, bounds will have to be imposed from outside by voters and involve replacing the incumbent. Variation in the seriousness of obstacles to such replacement is already reflected in the position of the $\mathbf{T}_{\mathbf{j}}$ lines.

\section{Systemic effects of yardstick competition}

A reflection on the consequences of a complete absence of yardstick competition may help become more aware of the systemic impact of its presence. Such thought experiment was already suggested in Salmon (1987) but for a different purpose than the one set here. More than reducing slack, discretion or rent-seeking (which was the main concern in that paper), the effects of yardstick competition stressed here are about changes in the way politicians seek support from the population and allocate their attention or effort across policies

\subsection{Voters' predicament in the absence of yardstick competition}

Assume information asymmetry between voters and self-interested office-holders and a total absence of cross-jurisdiction comparisons and yardstick competition. In such setting, voters have two ways to form an opinion on the performance of current incumbents. One is to rely on comparisons over time. The other is to rely on information supplied by interest groups.

Comparisons of outcomes over time may be useful to assess the performance of government in some domains or for some issues -- for instance, managing ethnic conflicts. In general, however, their effectiveness is problematic because outcomes are also driven by exogenous, variable and unknown forces. Some policy domains and sets of issues are especially affected by the problem. This is especially the case of 
macroeconomic variables. In particular, judging the performance of a government (or of a political regime for that matter) from the observed evolution of living conditions is particularly problematic.

Because of free-riding incentives, many interest categories do not get mobilized into efficiently organized groups (Olson 1965). An implication is that voters are unequal in their access to information. Farmers, say, get organized while a broader interest category, citizens interested in economic growth, say, is not. In the domain of interest of an organized group, its leadership can certainly overcome many of the information obstacles that ordinary citizens would encounter. Inasmuch as leaders share information with members, the latter are relatively well informed on matters of interest to them. Thus, overall, some voters are systematically better informed than others on some policies. Under the assumptions made at the outset, we can expect government to pay serious attention to the interests of organized groups and relatively little to members of unorganized categories.

Another implication of the mobilization problem is the involvement of government in its solution. If we take the free-riding obstacle seriously, why, or how, can a large category such as farmers succeed in overcoming that obstacle and get organized? Large interest categories often succeed in becoming and remaining mobilized groups thanks to exchange relations between politicians (or departments within government) and the leadership of these groups. Among the items supplied by the leadership of the groups in the context of these exchanges, a major category concerns the content, presentation and interpretation of the information about governmental policies that the leadership circulates within the group. For office-holders seeking support, this increases the comparative advantage of allocating attention and channelling resources to organized groups rather than to unorganized categories. But another consequence is that, in an informationally closed society, information about government policies that members of organized groups receive from their leadership is unlikely to be objective. In other words, although it is less severe than when there is no mobilization, the information asymmetry problem encountered by voters in their assessment of government applies also here. 


\subsection{A model $^{9}$}

The bias generated in the attention devoted by government to the different policy areas can be analysed with the help of the following model. Government is constrained by its access to a fixed resource $R_{T}$. It divides it into three different uses:

- promoting a macroeconomic goal such as economic growth $\left(R_{Y}\right)$,

- transacting with interest groups $\left(R_{G}\right)$,

- discretionary use $\left(R_{U}\right)$, -- e.g., slack, rents, foreign policy, etc.

In other words, the budgetary constraint is

$$
R_{T}=R_{Y}+R_{G}+R_{U}
$$

In association with the employment of unspecified exogenous specific factors, the use of $R_{Y}$ produces a macroeconomic outcome $Y$ and the use of $R_{G}$ a level $G$ of transactions with interest groups:

$$
Y=Y\left(R_{Y}\right) \text { and } G=\mathrm{G}\left(R_{G}\right) .
$$

Both $Y$ and $G$ increase electoral support $S$. In other words:

$$
S=S(Y, G) \text {. }
$$

Office-holders are interested only in $R_{U}$, which however depends on their remaining in power. This requires a level of electoral support $S^{*}$. The objective of government is thus

$$
\operatorname{Max} R_{U}=R_{T}-R_{Y}-R_{G} \quad \text { subject to } S(Y, G) \leq S^{*}
$$

In Figure 2, the budgetary constraint (1) appears in the SW quadrant in the form of triangle OMM'. Relations (2) between $R_{Y}$ and $Y$ and between $R_{G}$ and $G$ are represented, respectively, by curve $\mathbf{O F}$ in the NW quadrant and curve $\mathbf{O V}$ in the SE quadrant. If government kept no part of the resource for other uses than these two, any distribution between the two would be represented by a point along the budget constraint $\mathbf{M M}^{\prime}$ and would yield a combination of $G$ and $Y$ along the production-possibilities frontier $\mathbf{T T}^{\prime}$ in the NE quadrant. However, as noted, government maximises $R_{U}$ and needs only a level of support $S^{*}$ - represented by curve $S^{*}$ in the same quadrant. That level of support can also be expressed in terms of inputs, that is, by curve $\mathbf{s}^{*}$ (graphically derived from $\mathbf{S}^{*}$ ) in the SW quadrant. The distribution of $R_{T}$ that maximizes $R_{U}$ under the constraint of $\mathbf{s}$ * is point $\mathbf{a}$, from which one can in turn derive point $\mathbf{A}$.

\footnotetext{
9 The model is a modified version of a model included in Salmon (1991). In both cases the formal framework is inspired by the specific-factors model of Ronald Jones (1971).
} 


\section{[Figure 2 about here]}

In the absence of information about what obtains abroad, curve $\mathbf{S}^{*}$ is almost vertical. Voters are uncertain about governmental efforts both with regard to $Y$ and to $G$ but they are more uncertain with regard to $Y$. Thus variations in $Y$ have less impact on support than variations in $G$. For a marginal variation in the resource to have the same effect in terms of support whether the resource is spent on $Y$ or on $G$ (condition of interior equilibrium) one must be very close to the horizontal axis in the $\mathbf{N E}$ quadrant, or to the vertical axis in the $\mathbf{S W}$ quadrant - that is, government must devote little resources to $Y$. In other words, as showed in the context of multi-tasking by Holmstrom and Milgrom (1991), the less assessable task is sacrificed.

As an extreme case, curve $\mathbf{S}^{*}$ is perfectly vertical and curve $\mathbf{s}^{*}$ horizontal. Variations in macroeconomic performance have no effect on support and, consequently, on the resource devoted to that objective. Then, equilibrium corresponds to point $\mathbf{A}$ somewhere on $\mathbf{O T}^{\prime}$ and point a situated on $\mathbf{O M}$ '. Some resource $R_{U}$ is normally left to be employed discretionarily by office-holders.

When we move conceptually from that informationally closed society to one in which outcomes can be compared by voters with outcomes elsewhere, there are four clear-cut effects:

- the ability of voters to assess macroeconomic performance improves considerably;

- the ability of members of special interest groups to assess government performance with regard to their special interests improves somewhat (comparisons with other jurisdictions may be useful to check information provided by group leaders and induce them to be somewhat more truthful);

- thus, voters are more capable of assessing government performance overall;

- government allocates more resources to macroeconomic performance, and macroeconomic performance improves.

Two additional effects are ambiguous:

- the level of transactions with interest groups may increase or (because of the change in relative assessment capability) decrease, 
- the level of discretionary resources (rents, etc.) decreases if the level of transactions with interest groups does not but it may increase otherwise.

However, if yardstick competition over macroeconomic performance is intense, any ambiguity is dissipated. All resources are dedicated to that single dimension, and both the level of transactions with interest groups and discretionary resources are wiped out. In Figure 2, curve $\mathbf{S}^{*}$ becomes horizontal and touches the frontier in $\mathbf{T}$.

\subsection{Discussion}

The counterfactual of vertical support curves (just discussed) is often the world implicitly imagined in public choice writings. In that worldview, office-holders transact with interest groups, which constitute a subset of interest categories, and keep some resources for their own discretionary uses. As a consequence, worthy general interest objectives such as economic growth are sacrificed. The analysis justifies strongly distrusting government and all the usual normative or prescriptive implications of such distrust. But if that a priori, deductive, reasoning seems convincing, it is only because of the implicit and apparently innocuous assumption that there is only one jurisdiction or that the fact that there are several does not matter.

In reality, there are many countries and none is completely isolated. Some information always comes in from abroad and, as stressed in Section 3, much more would readily come in if policies crossed some bounds. The world assumed in the model is counterfactual also for another reason. In a single-country world or in a country closed to information from abroad, it is unlikely that people would remain for ever unaware of the ensuing bias. They would probably adopt some institutional arrangements (checks and balances, constitutional preservation of markets, etc.) that would mitigate its effects. In particular, they would probably adopt some form of decentralization or federalism, which would introduce yardstick competition at the subnational level.

It must noted that the case of intense yardstick competition, yielding horizontal support curves, discussed at the end of subsection 4.3 is also counterfactual and in part for the same reason. Salmon (1991) argues that citizens would become aware of the consequences of a voter-induced obsession with growth, menacing everything else. 
They would adopt institutions (corporatism, federalism, checks and balances, constitutional rules, e.g.) protecting some level of transactions with interest groups.

\section{Conclusion}

Yardstick competition among governments has been studied almost exclusively within the confines of fiscal federalism and public finance. It is very important that it has been found significant in that setting. I have suggested, however, that the mechanism is also significant, and perhaps even more so, in a broader context. Even in the case of governments trying to mimic others over a single variable, many other variables get involved as indirect effects of the mechanism or as instruments in the mimicking process. I have also tried to show that yardstick competition can be latent without being ineffective. Its major effect, then, is to set bounds to the choices that office-holders might contemplate. The existence of such bounds is not without consequences, even from a practical perspective -- for instance for prospective investors. Finally, I have argued that the political and economic system would not be the same if voters could not make comparisons across jurisdictions and if there were no yardstick competition, even if only of the latent variety. In that sense the mechanism is an essential, even if hidden, component of the system. Clearly, although valuable work has been done on the subject, more seems warranted.

\section{References}

Allers, Maarten A. and J. Paul Elhorst (2005). "Tax mimicking and yardstick competition among local governments in the Netherlands", International Tax and Public Finance 12: 493-513.

Allers, Maarten A. and J. Paul Elhorst (2011). "A simultaneous equations model of fiscal policy interactions", Journal of Regional Science 51, 271-91.

Ashworth, John and Bruno Heyndels (1997). "Politicians' preferences on local tax rates: an empirical analysis", European Journal of Political Economy 13: 479502.

Bartolini, David and Raffaella Santolini (2012). "Political yardstick competition among Italian municipalities on spending decisions", The Annals of Regional Science 49(1): 213-35.

Bhaskar, Roy (1975). A Realist Theory of Science. Eastbourne: Harvester Press.

Besley, Timothy and Anne Case (1995). "Incumbent behavior: vote-seeking, taxsetting, and yardstick competition", American Economic Review 85(1), 25-45. 
Besley, Timothy and Michael Smart (2007). "Fiscal restraints and voter welfare", Journal of Public Economics 91: 755-73.

Bordignon, Massimo, Floriana Cerniglia and Federico Revelli (2003). "In search of yardstick competition: a spatial analysis of Italian municipal property tax setting", Journal of Urban Economics 54: 199-217.

Bosch, Núria and Albert Solé-Ollé (2007). "Yardstick competition and the political costs of raising taxes: an empirical analysis of Spanish municipalities", International Tax and Public Finance 14: 71-92.

Breton, Albert (1996). Competitive Governments: An Economic Theory of Politics and Public Finance, Cambridge and New York: Cambridge University Press.

Breton, Albert (2006). "Modelling vertical competition", in: Ehtisham Ahmad and Giorgio Brosio (eds), Handbook of Fiscal Federalism, Cheltenham: Edward Elgar, pp. 86-105.

Breton, Albert and Angela Fraschini (2003). "Vertical competition in unitary states: the case of Italy", Public Choice 114 (1-2): 57-77.

Cartwright, Nancy (1983). How the Laws of Physics Lie. Oxford: Oxford University Press.

Elhorst, J. Paul and Sandy Fréret (2009). "Evidence of political yardstick competition in France using a two-regime spatial Durbin model with fixed effects", Journal of Regional Science 49 (5): 931-51.

Feld, Lars P., Jean-Michel Josselin and Yvon Rocaboy (2003). "Tax mimicking among regional jurisdictions", in: A. Marciano and J.-M. Josselin (eds), From Economic to Legal Competition: New Perspectives on Law and Institutions in Europe, Cheltenham: Edward Elgar, pp.105-119.

Fiva, Jon H. and Jorn Rattso (2007). "Local choice of property taxation: evidence from Norway", Public Choice 132: 457-70.

Foucault, Martial, Thierry Madies and Sonia Paty (2008). "Public spending interactions and local politics: empirical evidence from French municipalities," Public Choice 137: 57-80.

Geys, Benny (2006). "Looking across borders: a test of spatial policy interdependence using local government efficiency ratings", Journal of Urban Economics 60: 443-62.

Giere, Ronald N. (1985). "Constructive realism", in: Paul M. Churchland and Clifford W. Hooker (eds), Images of Science, Chicago: University of Chicago Press, pp. 75-98.

Hindriks, Jean and Ben Lockwood (2009). "Decentralization and electoral accountability: incentives, separation and voter welfare", European Journal of Political Economy 25: 385-97

Holmstrom, Bengt and Paul Milgrom (1991). "Multitask principal-agent analyses: incentive contracts, asset ownership, and job design", Journal of Law, Economics, and Organization 7, Special Issue: 24-52.

Jones, Ronald W. (1971). "A three factor model in theory, trade, and history", in: J. Bhagwati, R.W. Jones, R.A. Mundell and J. Vanek (eds), Trade, Balance of Payments, and Growth, Amsterdam: North Holland, pp. 3-21.

Maskin, Eric, Yingyi Qian and Chenggang Xu (2000). "Incentives, information, and organizational form", Review of Economic Studies 67(2): 359-78. 
Olson, Mancur (1965). The Logic of Collective Action: Public Goods and the Theory of Groups. Cambridge, Mass.: Harvard University Press.

Popper, Karl R. (1963). Conjectures and Refutations: The Growth of Scientific Knowledge. London: Routledge and Kegan Paul.

Revelli, Federico (2002). "Local taxes, national politics and spatial interactions in English district election results", European Journal of Political Economy 18: 281-99.

Revelli, Federico (2012). "Geografiscal federalism”, MS

Revelli, Federico and Per Tovmo (2007). "Revealed yardstick competition: local government efficiency patterns in Norway," Journal of Urban Economics 62: 121-34.

Salmon, Pierre (1987). "Decentralisation as an incentive scheme", Oxford Review of Economic Policy 3(2): 24-43.

Salmon, Pierre (1991). "Checks and balances and international openness", in: A. Breton, G. Galeotti, P. Salmon and R. Wintrobe (eds), The Competitive State, Dordrecht: Kluwer, pp. 169-84.

Salmon, Pierre (1997). "Democratic governments, economic growth and income distribution", in: A. Breton, G. Galeotti, P. Salmon and R, Wintrobe (eds), Understanding Democracy: Economic and Political Perspectives, Cambridge and New York: Cambridge University Press, pp. 144-60.

Salmon, Pierre (2006). "Political yardstick competition and corporate governance in the European Union", in: G. Ferrarini and E. Wymeersch (eds), Investor Protection in Europe, Oxford: Oxford University Press, pp. 31-58.

Salmon, Wesley C. (1984). Scientific Explanation and the Causal Structure of the World. Princeton: Princeton University Press.

Santolini, Raffaella (2009). "The political trend in local government tax setting", Public Choice 139: 125-34.

Solé-Ollé, Albert (2003). "Electoral accountability and tax mimicking: the effects of electoral margins, coalition government, and ideology", European Journal of Political Economy 19: 685-713.

Vermeir, Jan and Bruno Heyndels (2006). "Tax policy and yardstick voting in Flemish municipal elections", Applied Economics 38 (19/20): 2285-98.

Wrede, Matthias (2001). "Yardstick competition to tame the Leviathan", European

Journal of Political Economy 17: 705-21. 


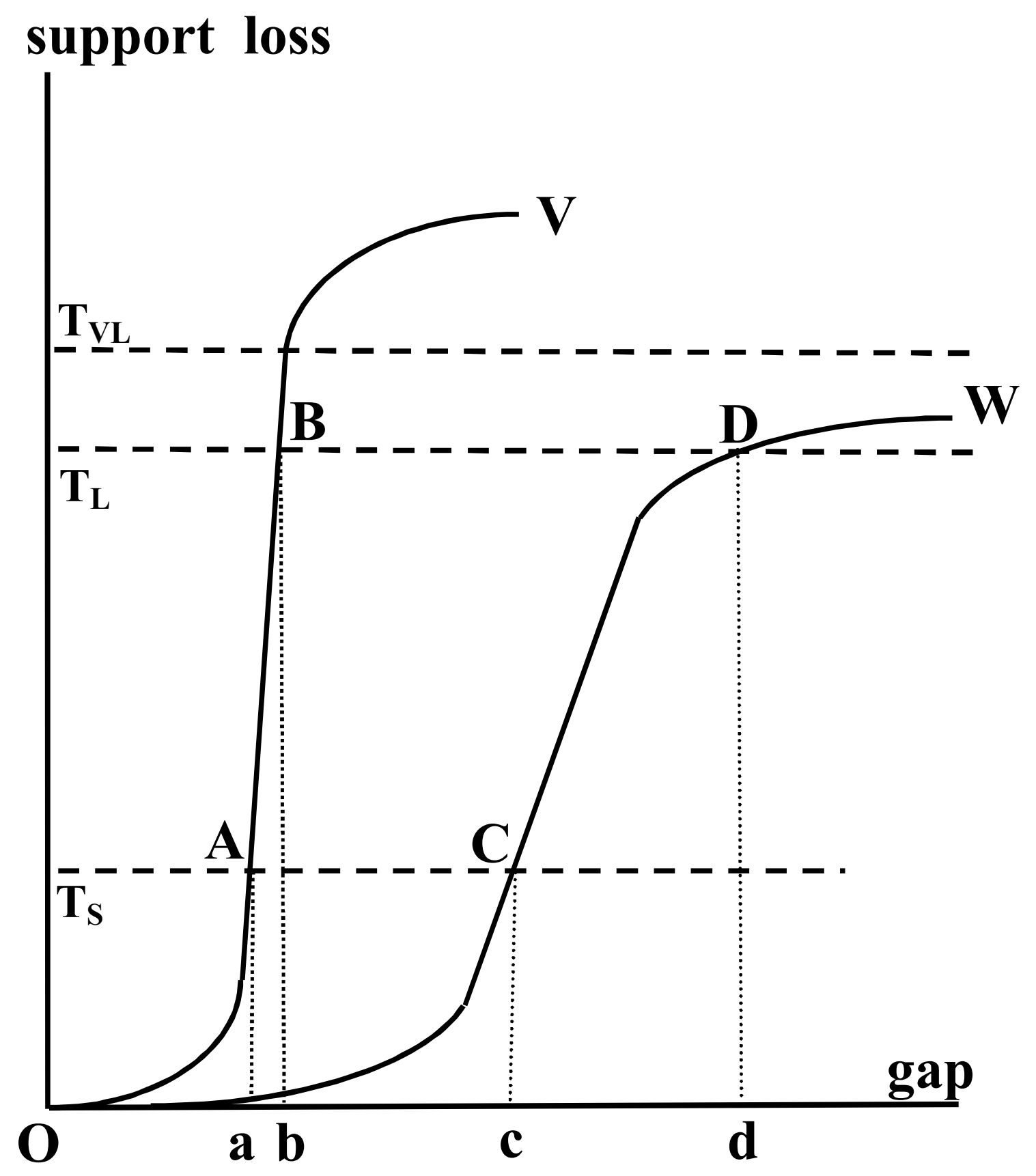

Figure 1: Bounds to negative performance 


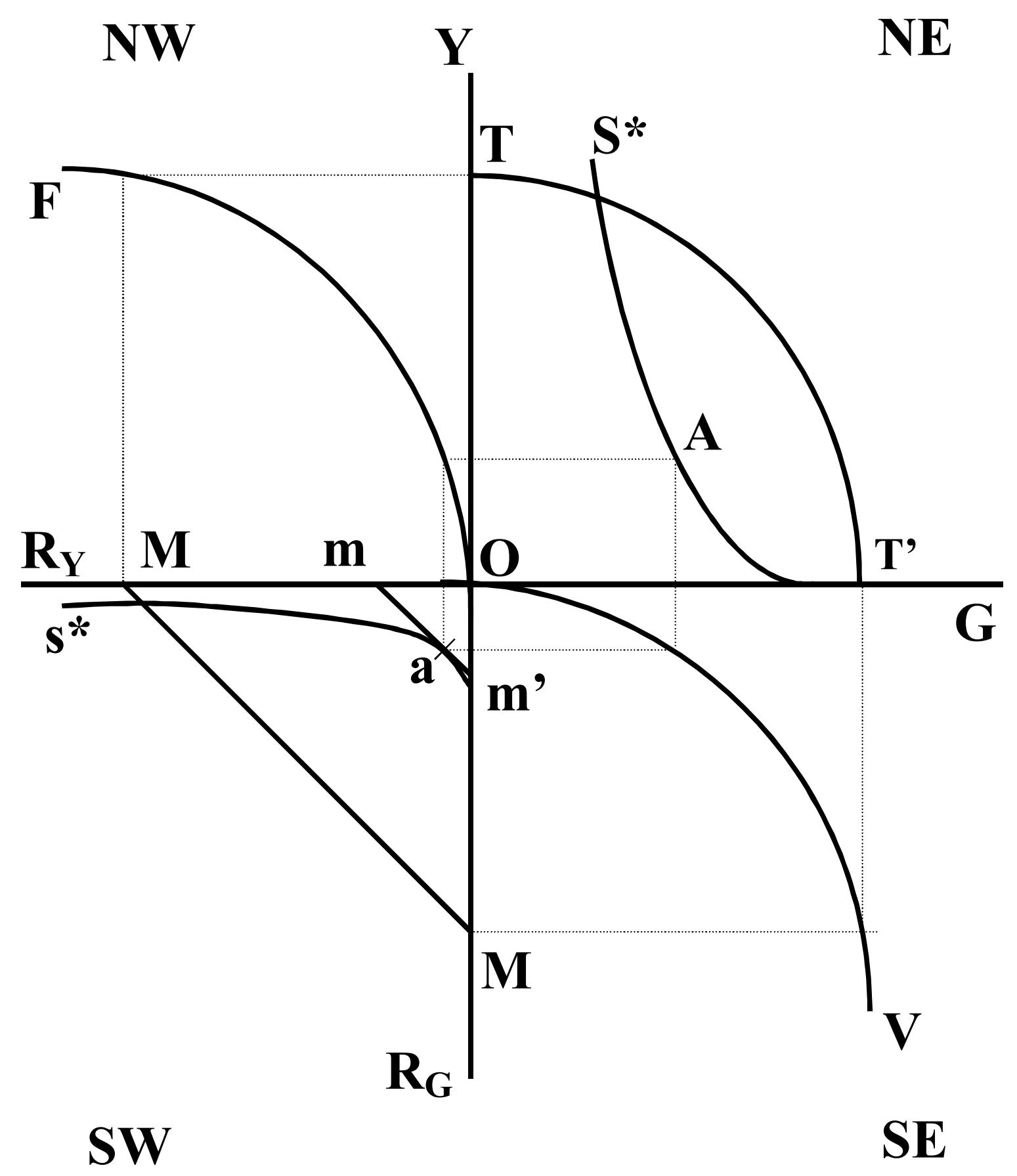

Figure 2: Allocation of effort when no yardstick competition 